\title{
New Technologies in the Instruction of History in Primary Education
}

\author{
Maria Kotsira, Klimis Ntalianis, Vasiliki Kikili, Filotheos Ntalianis, Nikolaos Mastorakis \\ Received: January 29, 2021. Revised: February 25, 2021. Accepted: March 8, 2021. Published: March 10, 2021.
}

\begin{abstract}
Nowadays, the exploitation of augmented reality in education is linked to a multitude of pedagogical subjects, including history, geography, natural sciences and arts. The extensive use of computers in the educational process in recent years, in addition to learners' familiarity with the use of Internet and applications associated with its operation, have led to a search for creative methods, which will enhance interaction in the pedagogical approach. As a result, a digital learning environment has emerged in which trainees gain access to knowledge in an entertaining and interactive way by making use of innovations and gaining the ability to control their knowledge. The purpose of this paper is to feature the role of new technologies in the educational process by studying the use of augmented reality applications in teaching history. Designing such applications requires direct involvement of the teacher and, as established by the case study, the benefits are extremely important; students acquire a particular interest in the learning object and achieve higher performance, as compared to conventional forms of teaching.
\end{abstract}

Keywords - pedagogical subject, history, educational process, new technologies, augmented reality.

\section{INTRODUCTION}

$\mathrm{T}$ HE teaching of History in primary school consists the first contact of children with historical events and aims to cultivate the development of historical thinking and historical consciousness from an early age in primary school. Through study and engagement with History and historical events, students will realize that the modern world and the past are not separate but the former is a continuation of the latter.

The evolution of technology (computers, tablets, smartphones, etc.) and its widespread use, even by young

This work was supported in part by Interbit Research (http://www.interbitresearch.com/).

M. Kotsira is with the University of West Attica, Egaleo, Athens, Greece (e-mail: mscedt19042@uniwa.gr).

K. Ntalianis is with the Department of Business Administration, University of West Attica, Egaleo, Athens, Greece (e-mail: kntal@ uniwa.gr).

V. Kikili is with the Ministry of Education and Religious Affairs, Directorate of Primary Education, Athens, Greece (e-mail: vasikik@gmail.com).

F. Ntalianis is with the Department of Business Administration, University of Piraeus, Piraeus, Greece (e-mail: filotheos@unipi.gr).

N. Mastorakis is with the Industrial Engineering Department, Technical University of Sofia, Sofia, Bulgaria (e-mail: mastor@tu-sofia.bg) students, has led teachers to employ new technologies when designing their teaching in order to make it more engaging and stimulate the interest of primary school students. Thus, in recent years a new form of new technologies has emerged; applications of augmented reality. Augmented reality is the projection of a subject with an image enhanced by information and virtual characters designed on a computer. Digital objects give the impression that they exist in the same space as realworld objects. The displayed information consists of sounds, texts and videos. Information can be viewed either on devices such as tablets and smartphones or through special Augmented Reality glasses. What makes the augmented reality experience special is that the user interacts with the physical world in the same way as if he were actually inside it. However, digital information is usually placed in this world in order to augment it with things we would not normally see, hear, touch or feel.

In this paper, the introduction of new technologies in learning is discussed- with particular reference to augmented reality - and the extent to which new technologies and augmented reality in particular have been applied so far in learning for primary school children. In Greece, despite the fact that there has been some progress towards making use of augmented reality technologies, there is still much room for improvement, as a large number of teachers are still skeptical. This paper, therefore, aims to remove these limitations by demonstrating the positive outcomes that result from the use of new technologies, with regard to the improvement in student performance, the strengthening of team spirit, but also the increase in the degree of interest.

\section{THE USE OF AUGMENTED REALITY APPLICATIONS FOR EDUCATIONAL PURPOSES}

The term "augmented reality" was introduced for the first time in 1992 at a scientific conference by the staff of Boeing. The real cause was an application- amplifier of the user's visual field in order to provide the necessary data for the implementation of their work (Caudell and Mizell 1992).

Augmented reality is the combination of the real and virtual environment (R. T. Azuma 1997). Augmented reality is not a substitute of the real world but contributes to its enhancement, while the user has a perception of this environment blended with virtual objects (M. Billinghurst 2002). In addition, through the use of virtual graphics the virtually created environment is connected with the user's visual-audio real 
world (Chang, Morreale and Medicherla 2010). In other words, the use of augmented reality does not require the user's isolation in a virtual environment. (Koller, et al. 1997) On the contrary, it contributes to the enhancement of the real world by providing data and information. (Hoff, Nguyen and Lyon 1996).

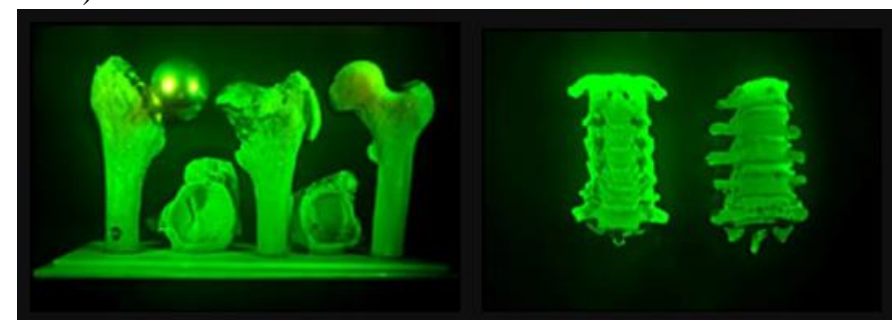

Figure 1: Use of holograms for the construction of artificial joints (Source: http://www.hih.org.gr/el/holography/applications.html)

The first helmet of virtual reality was created in 1968, the user had access in data depicted in a 3D form able to change with a head movement (Sutherland 1968). This initial device has been developed and was gradually replaced by other ones called head up displays, these new devices were placed on the user's head with the user having to look straight forward. This certain type of augmented reality device was first used by air force pilots for the transfer of flight data (Swift 1983).

Since then these devices have been used in a wide range by companies as well as for educational purposes. (Lee 2012). Moreover, in 2013 an important development has been made since Google introduced for the first time the google glasses, that is, a high tech device of augmented reality (Steiner 2013). In 2015, the answer came from Microsoft which introduced the "HoloLens" an equivalent device that the user can put on his head enabled to see holograms. Nowadays, the most modern development is contact lenses which are about to replace hardto-use-screens (Lingley, et al. 2011).

The etymology of the word "hologram" has its roots in the Greek words "holo" meaning "all" and "grafein" meaning "to write". In particular, it is a technique, which is related to the ability to capture light waves, which are reflected in any material object, so that, when there is appropriate laser lighting, to produce a faithful three-dimensional copy that allows human eye to perceive the image as an element of reality (Hellenic Institute of Holography n.d.).

The holography was discovered in 1948 by the Hungarian engineer and physicist Dennis Gabor, who, several years later in 1971, was awarded with the Nobel Prize for this discovery, holography remained inapplicable for many years until lasers were discovered in early 1960s.

In modern times, holograms have numerous applications, they are used in studies to determine the strength of an aircraft, but also of entire nuclear reactors. Holograms are also applied, on a large scale, in the field of medicine, contributing to the use of new methods for the detection of tumors in patients who have been diagnosed with neoplastic diseases, but also in optimizing the methodology of creating artificial limbs.

Equally important is the application of holograms in dentistry. Indicatively figure 1.1 shows a model of the way in which artificial joints are made by using the technology of holograms.

In addition, holography is used to verify the authenticity of banknotes, credit cards, tickets and official documents, including passports. Nowadays, it is given that holograms will be used in a wider range of scientific fields, education among others (Hellenic Institute of Holography n.d.).

The introduction of new technologies in the educational sector was an inevitable development (Koustourakis and Panagiotakopoulos 2008), which contributed to the reconstruction of pedagogical methods (Gatzias 2000). Augmented reality is also included in the new technologies that are introduced at school which is inextricably linked to the constructivist learning approach. The use of augmented reality applications in the real environment enhances learning by allowing learners to form roles and develop skills that they find useful in everyday life (Lave and Wenger 1991). The rapid development of technologies like this of augmented reality makes extremely difficult their prediction of how will be evolved in the future. In addition, a certain fact is that it can't replace fully the physical presence of the teacher. Nevertheless, the combination of virtual reality can trigger the curiosity of students and keep their interest undiminished by creating a unique experience (PCmag 2016).

The use of augmented reality technologies in educational activities is directly related to the imagination and the creativity of teachers (Bacca, et al. 2014). Indicatively, in terms of science education, it could be used to simulate laboratory experiments. In addition augmented reality can also contribute effectively in teaching history or foreign languages by bringing students in contact with the cultures of the countries they study, enriching also teaching with audio and video.

Therefore, the use of augmented reality applications contributes to the crucial change of classic pedagogical approach. Therefore, the students can interact with virtual objects, which it would be impossible to come into contact in real life, due to possible dangers or distance, for example if these objects are located on different continents or planets or even time since these information concern past events, or even their size if the objects are big animals or giant constructions (Martin, et).

\section{BOOKS OF AUGMENTED REALITY}

Augmented reality books are available in the market. These books have as a subject the study of history of natural environment, space and arts. For the use of these books technically speaking, a tablet or a smartphone is necessary since a large part of augmented reality applications are compatible with android or iOS. Users through the use of QRcodes c scan certain points at these books and activate hotspots and digital material (videos and images). For example, as the user is reading the book can see also via a mobile device these certain digital material. Actually the book 
is the same but with some extra features like a three dimensional dinosaur moving on the book! (typothes.gr 2015)

In recent years, the use of augmented reality books is incorporated in the teaching method. In Greece, the SchoolAR application is considered an initial effort of integration into school textbooks, so that teachers and students could be familiarized with modern technologies.

School books have only two dimensional images printed on paper. The technology of augmented reality provides to the user a three dimensional object which can be shifted or magnified in a way that could be seen as more realistic (SchoolAR 2020).These applications are adapted to the curriculum of each educational unit while modernization of school textbooks is being achieved.

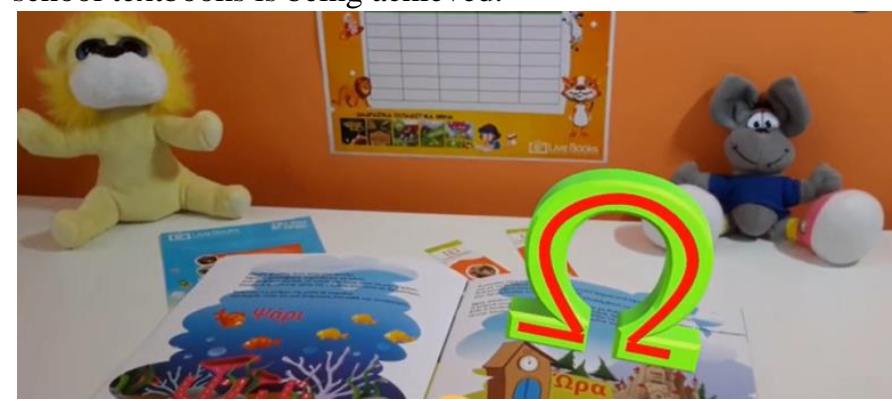

Figure 2: an example of an augmented reality book for learning to

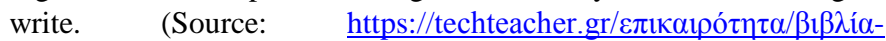

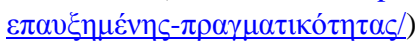

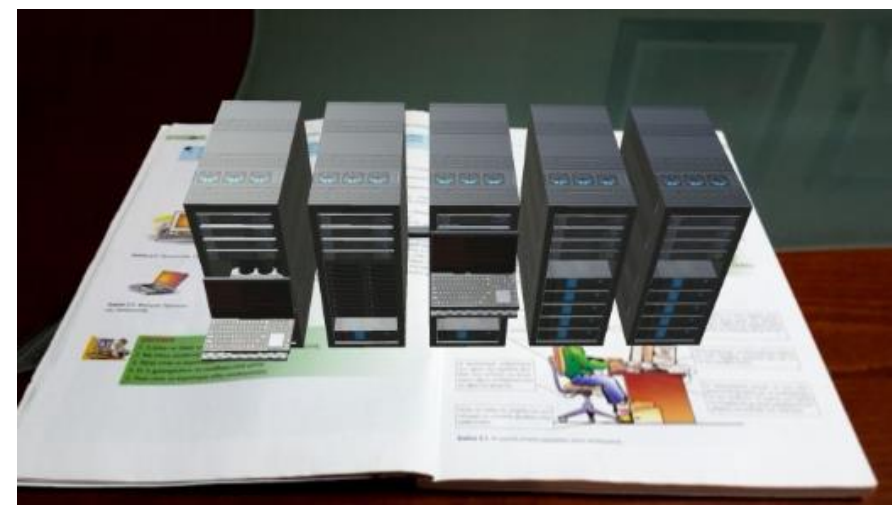

Figure 3: an example of an augmented reality textbook. Source: (http://users.sch.gr/samgeorg/schoolar/wordpress/ $\varepsilon \varepsilon \rho \gamma \rho \alpha \varphi \eta ́ /)$

\section{BENEFITS AND OBSTACLES FROM THE USE OF NEW TECHNOLOGIES IN EDUCATION}

The applications of new technologies offer to teachers and students a wide range of experiences that they couldn't have gained in the real environment allowing them to comprehend difficult terms (Rosenbaum, Klopfer and Perry 2007). Moreover according to a research, students show an increased interest as they use augmented reality applications, while as they are more focused and they tend to make greater efforts, resulting to a much better learning outcome(Serio, Ibáñez and Kloos 2013). In addition, according to many researches, it is proven that students by visualizing the concepts as well as interacting can manage to simplify them without having to study a conventional textbook (lee 2012). Moreover, students also develop skills, such as critical thinking, collaboration and logical sequencing (Wasko 2013).Another characteristic is that complicity among teachers and students is strengthened, while the configuration of the educational material allows the selfguided learning as well as the reflection in the most attractive way.

Despite the fact that this is not a newly developed technology, it was only in the last decade since it began to enter seriously in the educational field and according to the Horizon report in 2010 many advantages emerged in primary education (Johnson, Levine, et al. 2010).

In general, the use of augmented reality applications in order to create an interactive learning environment needs to be related to discovery learning (Durall, et al. 2012).According to this data static experience is prevented while as experimentation and participation of learners is enhanced, moreover learners gain the ability to live unique experiences (Liu, et al. 2007). An important fact is that these applications can be used inside and outside of the classroom. In addition, the use of these applications in teaching encourages informal learning and transforms education into entertainment by simulating natural phenomena, historical events or important personalities, so as value would be added to knowledge and enhancing students' mental and emotional development (Kaufmann 2003).

In any case, the use of these specific applications requires their simplification, so that a specialized knowledge would not be needed, to which teachers can't have an easy access. An indication of how familiar young people are with augmented reality features is the huge success of the POKEMON GO game, which was launched by nintendo in 2016 and within 15 days managed to gain over 20 million active users.

\section{RESTRICTIONS ON THE USE OF NEW TECHNOLOGIES IN EDUCATION}

Despite the positive outcome of the use of augmented reality applications in the pedagogical process, there are also some serious limitations (Ertmer and Ottenbreit-Leftwich 2010). This is mainly due to the fact that a significant percentage of teachers do not have the required knowledge regarding the use of technology, so it remains cautious about its adoption (Billinghurst and Duenser 2012). For this purpose, additional training of teaching staff is necessary. According to the findings of a literature review of publications from the mid1980 s to 1992 , teachers and professors, while having legitimate concerns, were positive about the introduction of new technologies in education (Dupagne and Krendl 1992). However, the majority of the educational community still believes that technology contributes with no doubt to the advancement of the pedagogical process (Preston, Cox and Cox 2000). In addition, a research from 2000 also shows that teachers' stress has a negative effect on their attitude (Venkatesh 2000). 
Moreover, as Baylor and Ritchie found in a study conducted in 2002 on 94 teachers from 12 schools in different US states, teachers who were willing to change, showed a positive attitude towards the integration of innovative technologies, however, they realized that training is necessary in order to learn the procedures so as to have a total and successful integration (Baylor and Ritchie 2002). Furthermore, as reported by Salmi, Kaasinen and Kallunki the use of new technologies in education and especially in the teaching of Natural Sciences is "quite effective and innovative" (Salmi, Kaasinen and Kallunki 2012).Furthermore, according to a recent survey, among 200 primary education officials, aged 25 to 35 , it was found that they were quite familiar with augmented reality applications, while they estimated that their opposition to change and a limited infrastructure worked inhibitory (Alkhattabi 2017).In Greece, since the beginning of 2000, projects have started to be implemented with the aim of integrating IT technologies and applications in the teaching process. It is generally estimated that teachers were willing to use them, given the fact that they will acquire the necessary training in order to gain the essential technical knowledge, which will enable them to respond to the new situation (Panagiotakopoulos, et al. 2005). Nevertheless, some issues are dealt with skepticism, both in terms of equipment as well as the existing pedagogical framework (Tzimogiannis 2002). Similarly, a recent research on future primary school teachers has shown that augmented reality applications do not show any difficulties in their use, while could save teaching time, but also providing incentives for learners to incorporate the new knowledge. (Díaz Noguera, Toledo Morales and Hervás Gómez 2017).

\section{NEW TECHNOLOGIES IN TEACHING OF HISTORY SUBJECT IN PRIMARY EDUCATION}

The main purpose of teaching a history lesson is the cultivation of historical thought, that is, the understanding of historical events through the interpretation of causes and effects. Learners understand that the modern world functions as a continuance of the past.

The teaching of this course is based on the learning theories of constructivism, learners seek literally to create knowledge by themselves through the interaction with open learning environments as well as the structuring of knowledge in existing cognitive patterns. Therefore, the teacher plays a supportive role by providing students with the necessary skills to develop their knowledge (Palikidis 2007).

In the last four grades of primary education in Greek schools, the teaching of the history lesson operates autonomously, students aim to get in touch with the most important Greek myths and to understand basic historical concepts as well as knowing great events, from antiquity to the present day, but also elements of cultures, with which they are associated. The units of the third grade of elementary school's history book refer to mythology including also the creation of the world, the exploits of Hercules and These us, the Argonaut Campaign, the Trojan War and the adventures of Ulysses, as well as prehistory, including Stone Age and Bronze Age. Additionally, the teaching of the Bronze Age's unit provides especially a wide range of possibilities for the use of new technologies, as will be briefly described below.

In general, history lesson shows among students significant failure rates in the exams of all school levels, a fact which can be attributed, to a certain extent, to the limited use of modern teaching methods (Fragoudaki 2014).According to the above mentioned fact the use of new technologies for the learning approach of the specific course is extremely important, as it contributes to the enhancement of holistic knowledge, as well as the modernization of the course. After all, learners in their daily life often use new technologies that emerges the desire to integrate them in the context of school teaching, which makes it necessary to use the applications that fall within the framework of discovery learning (Brunner 1966). At the same time, the teacher becomes a leader forming the necessary conditions for the active reception of learning (Economou, 2003).

Moreover, collaborative teaching and interaction of learners is achieved, which contributes to the increase of effectiveness in the learning process, compared to individual work (Kagan 1994). In order to integrate new technologies and, more specifically, the augmented reality technologies in the teaching of the history lesson of the 3rd grade of Primary School, especially in the teaching units of the Bronze Age, the students were divided into groups. In order to conduct the course, each group of children must have at least one smartphone or tablet. Networked computers are also required to assess pupils' knowledge. It should also be possible to print the work of children so that they can exhibit it on the class notice board. The units from the Third class history course that will be taught refer to the Cycladic culture, the Minoan culture and the Mycenaean culture that were created during the Bronze Age in Greece. The lessons of history, geography, language, aesthetic education and new technologies are involved in the teaching scenario as part of interdisciplinarity. The learning objectives are students to understand the specific characteristics of each civilization and to appreciate its contribution to the global culture, they should also be addicted to the observation and description of archaeological findings from different and diverse sources. Finally, they should be familiar with the use of software relating to the educational process. During the lesson, students are asked to scan images from their book so they could be transported with the help of Google earth applications to the regions where civilizations developed in the Mycenae, Crete and Cyclades. Moreover, in some other images, they can hear narrations referring to the figurines depicted from the book of S. Gialouraki "The Cycladic figurines come to life". Furthermore, in some other images they are transferred to the National Archaeological Museum and the Museum of Cycladic Art (https://cycladic.gr/) for a virtual tour from where they learn information about some 
Cycladic figurines. Images from the Minoan Civilization transfer them with augmented reality in the digi-past application of moptil, (www.moptil.com, www.digipast.com).Through the application, students take a virtual tour of the palace as it was before it was destroyed and also can experience life in the palace. The students feel like they live in the palace of Knossos and can visit all its spaces. Images from the Mycenaean civilization transfer them through videos to the Mycenae palace as well as on a virtual tour of the Pylos palace. After the presentation of all the civilizations, students were told to search for information, depending on the culture that impressed them with the help of google search. So, after the students' selection of works of each era, as seeking more information, they printed them to be displayed on a notice board inside the classroom. In addition, in the context of interdisciplinary learning and the art class, they dealt with the decoration of a vase or the formation of a mural within the standards of that period.

After the lesson of all three cultures is completed, each child is given an Assessment Sheet to evaluate what they have gained from the realization of this teaching scenario.

The results were very encouraging as the students successfully completed the Assessment Sheet. They also showed great interest in gathering information about works from all cultures, which they searched on the internet. Particularly encouraging was the fact that students who were not distinguished for their active participation in the educational process, made an intense effort by achieving higher performance and increasing their creativity.

\section{CONCLUSION}

Modern technologies can be a valuable tool for the development of the pedagogical approach, as they engage, activate, encourage and motivate students, in order to perceive the educational process through a variety of perspectives. Given, therefore, that augmented reality has been implemented in several applications, its introduction into the pedagogical field was inevitable. In general, augmented reality consists a copy of the real-world environment, augmented with additional elements related to digital data, such as audio, image and video files, which increase user interaction. In this context, the use of augmented reality books enhances the potential of printed books.

In Greece, even though the educational community has already realized that the combination of traditional education and technological applications contributes to the improvement of the cognitive process, augmented reality is not widely used.

A lesson plan integrating augmented reality applications was created for a History unit for the 3rd grade of primary school and the students were invited to develop critical thinking, to experiment, but also to develop their teamwork skills.

The results of the implementation of this action were particularly encouraging, as the students were able to largely consolidate through visualization the material being taught, combining academic knowledge with entertainment. Thus, this process has led to the enhancement, not only of their mental, but also of their emotional development, by actively involving the students in the educational process through encouraging teamwork and experimentation.

\section{ACKNOWLEDGMENT}

The authors would like to thank very much Interbit Research (http://www.interbit-research.com/) for its financial support to carry out this work.

\section{REFERENCES}

[1] Alkhattabi, M. «Augmented reality as e-learning tool in primary schools' education: Barriers to teachers' adoption», International Journal of Emerging Technologies in Learning (IJET), 2017.

[2] Azuma, R, Y Baillot, R Behringer, S Feiner, S Julier, B Maclntyre. «Recent advances in augmented reality», Precence: Teleoperators \& Virtual Environments, 2001.

[3] Azuma, Ronald T. "A survey of augmented reality», Presence: Teleoperators and Virtual Environments, 1997.

[4] Bacca, J, S Baldiris, R Fabregat, S Graf. «Augmented reality trends in education: a systematic review of research and applications», Educational Technology \& Society, 2014.

[5] Baylor, A. L., D. Ritchie. "What factors facilitate teacher skill, teacher morale, and perceived student learning in technology-using classrooms? », Computers \& Education, 2002

[6] Bidin, S., A. A. Ziden. «Adoption and application of mobile learning in the education industry», Procedia - Social and Behavioral Sciences, 2013.

[7] Billinghurst, M., A. Duenser. «Augmented reality in the classroom», Computer, 2012.

[8] Billinghurst, Mark. «Augmented reality in education», New horizons for learning, 2002.

[9] Billinghurst, Mark, Anders Henrysson. «Research directions in handheld AR», International Journal of Virtual Reality, January 2006.

[10] Billinghurst, Mark, Hirokazu Kato. «Collaborative augmented reality», Communications of the ACM, 2002.

[11] Brunner, J.S. Toward a Theory of Instruction. Cambridge: Harvard University Press, 1966.

[12] Bujak, K. R., I. Radu, R. Catrambone, B. Macintyre, R. Zheng, G. Golubski. «A psychological perspective on augmented reality in the mathematics classroom», Computers \& Education, 2013.

[13] Carmogniani, J, B Furht, M Anisetti, P Ceravolo, E Damiani, M Ivkovic. "Augmented reality technologies, systems and applications», Multimedia and applications, 2011.

[14] Caudell, Thomas P., David W. Mizell. «Augmented Reality: An application of head-up display technology to manual manufacturing processes», Sciences, In Proceedings of the twenty - fifth Hawaii International Conference on System. 1992.

[15] Chang, George, Patricia Morreale, Padmavathi Medicherla. «Applications of augmented reality systems in education», In Society for information Technology and Teacher Education International Conference. Association for the Advancement of Computing in Education (AACE). 2010.

[16] Chen, C. H., Y. Y. Chou, C. Y. Huang. «An Augmented-Reality-Based Concept Map to Support Mobile Learning for Science», The AsiaPacific Education Researcher, 2016.

[17] Cheon, J., S. Lee, S. M. Crooks, G. Song. «An investigation of mobile learning readiness in higher education based on the theory of planned behavior», Computers \& Education, 2012.

[18] Cox, M. J., C. Preston, K. Cox. «What Motivates Teachers to use ICT?», Paper presented at the British Educational Research Association Conference. Brighton, 1999.

[19] Delello, J. A. «Insights from pre-service teachers using science-based augmented reality», Journal of computers in education, 2014.

[20] Demetriadis, S.,. «Cultures in negotiation: teachers' acceptance/resistance attitudes considering the infusion of technology into schools», Computers \& Education, 2003. 
[21] DePriest, D. «The fifth dimension: How augmented reality is launching worlds within our world», Paper presented at the Technology, Colleges and Community Worldwide Online Conference. 2012.

[22] DíazNoguera, M. D., P. Toledo Morales, C. Hervás Gómez. «, M. D., P., \&, C. (2017). Augmented Reality Applications Attitude Scale (ARAAS): Diagnosing the Attitudes of Future Teachers», The New Educational Review, 2017

[23] Dunleavy, M., C. Dede, R. Mitchell. «Affordances and limitations of immersive participatory augmented reality simulations for teaching and learning», Journal of Science Education and Technology, 2009: 7-22.

[24] Dupagne, M., K. A. Krendl. «Teachers' attitudes toward computers: A review of the literature», Journal of research on computing in education, 1992.

[25] Durall, E., B. Gros, M. Maina, L. Johnson, S. Adams Becker. « Technology Outlook: Iberoamerican Tertiary Education 2012-2017. «, Austin, Texas:The New Media Consortium., 2012.

[26] Ertmer, P. A., A. T. Ottenbreit-Leftwich. «Teacher technology change: How knowledge, confidence, beliefs, and culture intersect», Journal of research on Technology in Education, 2010.

[27] Fernandez, M. «Augmented Virtual Reality: How to Improve Education Systems», Higher Learning Research Communications, 2017.

[28] Furió, D., S. González-Gancedo, M. Juan, I. Seguí, M. Costa. «The effects of the size and weight of a mobile device on an educational game», Computers \& Education, 2013.

[29] Giddens, Anthony, Mitchell Duneier, Richard Appelbaum. Introduction to Sociology. New York: W.W. Nortn and Company, 2007.

[30] Hall, Tracey E., Anne Meyer, David H. Rose. Universal design for learning in the classroom: Practical applications. Guilford Press., 2012.

[31] Hoff, William A, Khoi Nguyen, Torsten Lyon. «Computer-visionbased registration technigues for augmented reality. In Intelligent Robots and Computers Vision XV: Algorithms, Techniques, Active Vision, and Materials Halding», International Society for Optics and Photonics. 1996.

[32] Holden, C. «The local games lab ABQ: Homegrown augmented reality», TechTrends, 2014.

[33] Johnson, L., A. Levine, R. Smith, S. Stone. « The Horizon report: 2010 edition. «, New Media Consortium, 2010.

[34] Johnson, L., R. Smith, H. Willis, A. Levine, K. Haywood. «NMC Horizon Report: 2011 Edition. «, The New Media Consortium, 2011.

[35] Kagan, S. Cooperative Learning. San Juan Capristrano: CA: Kagan Cooperative Learning, 1994.

[36] Kamarainen, A. M., «EcoMOBILE: Integrating augmented reality and probeware with environmental education field trips», Computers \& Education, 2013

[37] Kaufmann, H. «Collaborative Augmented Reality in Education. «, In Proceedings of Imagina 2003 Conference. Monaco, 2003.

[38] Kesim, M., Y. Ozarslan. "Augmented reality in education: current technologies and the potential for education», Procedia - Social and Behavioral Sciences, 2012

[39] Kirkley, S. E., J. R. Kirkley. «, J. R. (2005). Creating next generation blended learning environments using mixed reality, video games and simulations», TechTrends, 2005.

[40] Klopfer, E, J Sheldon. «Augmenting your own reality: Student authoring of science - based augmented reality games», New directions for youth development, 2010.

[41] Koller, D, G Klinker, E Rose, D Breen, R Whitaker, M Tuceryan. «Real-time vision-based camera tracking for augmented reality applications «, In Proccedings of the ACM symposium on Virtual reality software and technology. 1997.

[42] Koutromanos, G., A. Sofos, L. Avraamidou. «The use of augmented reality games in education: a review of the literature», Educational Media International, 2015.

[43] Lave, J, E Wenger. Situated learning: Legitime peripheral participation. Cambridge: University Press, 1991.

[44] Lee, Kangdon. «Augmented reality in education and training», Tech Trends, 2012

[45] Lin, C. Y., «Augmented reality in educational activities for children with disabilities», Displays, 2016.

[46] Lingley, R A, «A single-pixel wireless contact lens display», Journal of Micromechanics and Microengineering, 2011.

[47] Liu, W., A. D. Cheok, C. L. Mei-Ling, Y. L. Theng. «Mixed reality classroom:learning from entertainment», In Proceedings of the 2nd international conference on Digital interactive media in entertainment and arts . ACM, 2007. 65-73.

[48] Martin, S, G Diaz, E Sancristobal, R Gil, M Castro, J Piere. «New technology trends in education: Seven years of forecasts and convergence», Computers \& Education, 2011.

[49] Martín-Gutiérrez, J., M. D. Meneses-Fernández. «Augmented Reality Environments in Learning, Communicational and Professional Contexts in Higher Education», Digital Education Review, 2014.

[50] McMahon, D.D., C. C. Smith, D. F. Cinak, R. Wright, M. M. Gibbons. «Effects of digital navigation aids on adults with intellectual disabilities: Comparison of paper map, Google maps, and augmented reality», Journal of Special Education Technology, 2015.

[51] Milgram, Paul, Fumio Kishino. «A taxonomy of mixed reality visual displays», IEICE TRANSACTIONS on Information and Systems, 1994.

[52] Mohnsen, Bonnie S. Using technology in physical education, 4th edition. Cerritos,. CA: Fitware, 2004

[53] PCmag. Augmeted reality in education. 2016. https://gr.pcmag.com/software/20168/augmented-reality-stenekpaideuse (last accessed: 11/4/2020).

[54] Pelgrum, W. «Obstacles to the integration of ICT in education: results from a worldwide educational assessment», Computers \& Education, 2001

[55] Pluckrose, H. Children Learning History. . England: Basil Blackwell Ltd, 1991.

[56] Preston, C., M. J. Cox, K. J. Cox. Teachers as Innovators: An evaluation of the motivation of teachers to use information and communications technologies. Croydon: King's College London and Mirandanet, 2000.

[57] Radu, I. «Augmented reality in education: A meta-view and cross-media analysis», Personal and Ubiquitous Computing, 2014.

[58] Rodden, T., K. Cheverst, K. Davies, A. Dix. «Exploiting context in HCI design for mobile systems. ", Workshop on Human Computer Interaction with Mobile Devices. 1998.

[59] Rosenbaum, E., E. Klopfer, J. Perry. «On location learning: Authentic applied science with networked augmented realities», Journal of Science Education and Technology, 2007.

[60] Roussos, P. «The Greek computer attitudes scale: construction and assessment of psychometric properties», Computers in Human Behavior, 2007

[61] Salmi, H., A. Kaasinen, V. Kallunki. «Towards an open learning environment via augmented reality (AR): Visualising the invisible in science centres and schools for teacher education», Procedia-Social and Behavioral Sciences, 2012

[62] Sayed, N A El, H H Zayed, M I Sharawy. «ARSC: Augmented reality student card», Computers \& Education, 2011.

[63] SchoolAR.

2020. http://users.sch.gr/samgeorg/schoolar/wordpress/\%CF\%80\%CE\%B5\%C F\%81\%CE\%B9\%CE\%B3\%CF\%81\%CE\%B1\%CF\%86\%CE\%AE/ (last accessed: $15 / 10 / 2020)$

[64] Schrader, P. G. «, P.G. (2008).Learning in technology: Reconceptualizing immersive environments», AACE Journal, 2008.

[65] Serio, A. Di, M. B. Ibáñez, C. D. Kloos. «Impact of an augmented reality system on students' motivation for a visual art course», Computers \& Education, 2013.

[66] Sheng, B., L. Xia, P. Li, R. Shen. «Potential for Augmented Reality in Education: An Overview. s», EAI Endorsed Transactions on Future Intelligent Educational Environment, 2015.

[67] Sotiriou, S., F. X. Bogner. «, S., \&, F. X. (2008). Visualizing the invisible: augmented reality as an innovative science education scheme», Advanced Science Letters, 2008.

[68] Starner, Thad. «Project glass: An extension of the self», IEEE Pervasive Computing, 2013.

[69] Sutherland, Ivan E. «A head-mounted three dimensional display», In Proccedings of Fall Joint Computer Conference. 1968. 757-764.

[70] Swift, David W. Head-up displays. DC: U.S. Patent and Teademark Office. Washington. 1983.

[71] Thornton, T, J V Ernst, A C Clark. «Augmented reality as o visual and spatial learning tool in technology education», Technology and Engineering Teacher, 2012

[72] «typothes.gr», 2015. https://www.typosthes.gr/oikonomia/84581_bitari-startup-apo-ti-thessaloniki-poy-zontaneyei-toys-iroes-ton-biblion (last accessed: 15/10/2020) 
[73] Venkatesh, V. «Determinants of perceived ease of use: Integrating control, intrinsic motivation, and emotion into the technology acceptance model», Information systems research, 2000.

[74] Vinumol, K, A Chowdhury, R Kambam, V Muralidharan. «Augmented reality based interactive text book: An assistive technology for students with learning disability», In XV Symposium on Virtual and Augmented Reality. 2013.

[75] Wasko, C. «What teachers need to know about augmented reality enhanced learning environments», TechTrends, 2013.

[76] Wu, Hsin Kai, Silvia Wen Yu Lee, Hsin Yi Chang, Yyh Chong Liang. «Current status, opportunities and challenges of augmented reality in education», Computers and education, March 2013.

[77] Yuen, S., G. Yaoyune-yong, E. Johnson. «Augmented reality: An overview and five directions for AR in education», Journal of Educational Technology Development and Exchange, 2011.

[78] Gatzias, George. New technology, Cultural Management and New Economy. The Digital Communication and The New Media in The Greek Information Society. London: Louizou Publications, 2000. (In Greek)

[79] Drakopoulos, B. and P.B. Sioulas. "The Augmented Reality in Students with special learning difficulties"11th Conference on Informatics in Education 2019. 2019. (In Greek)

[80] Greek Institute of Holography. http://www.hih.org.gr/el/holography/holography-introduction.html. (In Greek)

[81] Koustourakis, G. and X. Panagiotakopoulos. :" The Information Communication Technologies in Primary Education : Effects and Problems from trying to implement in the pedagogical practice." 4th National Conference of Computer Science Teaching, New Technologies. Patra: University of Patras, 2008(In Greek)

[82] Koutsogiannis, D. " The rhombus of language education. Studies on the greek language ." Proccedings of the 32nd meeting of the linguistics sector. Thessaloniki, 2012 (In Greek)

[83] Konstantinou, K, and Aggeli X. " The Educational Design of Computer Learning Environments for Students with Dyslexia." Proceedings of the 5th Conference E.T.P.E. " Information and Communication technologies in Education" Thessaloniki : E.T.P.E., 2006. (In Greek)

[84] Makrakis, B. Hypermedia in Education. A social - constructive approach. Athens: Metechmio, 2000. (In Greek)

[85] Matsagouras, I. Collaborative teaching. Athens. Publications Grigori, 1995(In Greek)

[86] Mavroskoufis, K.D. Looking for the traces of History : historiography, teaching methodology and historical sources. Thessaloniki : Kyriakidis Bros, 2005(In Greek)

[87] Mikropoulos, T. A. The computer as a cognitive tool. Athens: Ellinika Grammata, 2006 (In Greek)

[88] Moustakas, K. I. Paliokas, D Tzovaras, and A. Tsakiris. Graphics and virtual reality. Athens : Association of Greek Academic Libraries, 2015 (In Greek)

[89] Palikidis, A. " The illustration of the school history books" The teaching of history in Greece and the research in school books. 321-362. Athens: Metexmio, 2007. (In Greek)

[90] Panagiotakopoulos, C, C. Alexopoulos, C. Goutsos, A. Skaltsas, and D. Tasios. "Information Society Technologies: How ready are our teachers to apply them in school practice?" Scientific yearbook of P.D.P.E. The School of Humanities and Social Sciences of the University of Patras , 2005. (In Greek)

[91] Siscos, A., and Antoniou, P., "New Technologies and the teaching of physical education." Searches in physical education and sports, 2006:311-325(In Greek)

[92] Tzimogiannis, A. "Preparing the school of the Information Society.Towards a complete model of integration of information and communication technologies in the Greek educational system." Modern Education, 2002. (In Greek)

[93] Fragoudaki, A.: "How to teach History." The books' journal, 2014. (In Greek)

\section{Creative Commons Attribution License 4.0 (Attribution 4.0 International, CC BY 4.0)}

This article is published under the terms of the Creative Commons Attribution License 4.0

https://creativecommons.org/licenses/by/4.0/deed.en_US 